\title{
Postocclusive Reactive Hyperaemia of Cutaneous Blood Flow in Premature Newborn Infants
}

\author{
G. C. M. BEAUFORT-KROL ${ }^{1}$ H. E. SUICHIES, ${ }^{2}$ J. G. AARNOUDSE, ${ }^{2}$ \\ A. OKKEN, ${ }^{1}$ H. W. JENTINK ${ }^{3}$ and J. GREVE: ${ }^{3}$ \\ From the ${ }^{1}$ Division of Neonatology, Department of Pediatrics, ${ }^{2}$ Department of Obstetrics and \\ Gynaecology, University Hospital Groningen and ${ }^{3}$ Department of Applied Physics, \\ Twente University of Technology, Enschede. The Netherlands
}

\begin{abstract}
Beaufort-Krol, G. C. M., Suichies, H. E., Aarnoudse, J. G., Okken, A., Jentink, H. W. and Greve, J. (Departments of Obstetrics and Paediatrics, University Hospital, Groningen, and Department of Applied Physics, Enschede, The Netherlands). Postocclusive reactive hyperaemia of cutaneous blood flow in premature newborn infants. Acta Paediatr Scand Suppl 360: 20, 1989.
\end{abstract}

Reactive hyperaemia, which occurs after a period of arterial occlusion is the result of an autoregulatory mechanism, involving local factors and autonomic nerve system control. To determine this autoregulatory mechanism in cutaneous blood flow in premature newborns we measured the cutaneous reactive hyperaemia response after a 1 min occlusion, using a diode laser Doppler flowmeter applied to the skin. Twentyfour infants with a gestational age ranging from 25 to 37 weeks and a postnatal age of 0.3 to 72 days were studied. The reactive hyperaemia response is described by the parameters maximal cutaneous blood flow $\left(V_{\max }\right)$, the time to reach maximal flow $\left(t_{\max }\right)$, the time taken for blood flow to return to baseline following $V_{\max }\left(t_{\mathrm{end}}\right)$ and the \% increase in cutaneous blood flow above preocclusional level (overshoot). A cutaneous reactive hyperaemia response could be elicited in all infants. Following occlusion the $V_{\max }$ was $2640 \pm 1050 \mathrm{mV}($ mean $\pm \mathrm{SD})$, the $t_{\max }$ was $7.6 \pm 3.9 \mathrm{sec}$ (mean $\left.\pm \mathrm{SD}\right)$, the $t_{\text {end }}$ was $35.6 \pm 14.6 \mathrm{sec}$ (mean $\pm \mathrm{SD}$ ) and the overshoot was $74.6 \pm 34 \%$ (mean \pm SD). A negative correlation was found between hematocrit and $t_{\max }(r=-0.62$, $p<0.01)$. No influence of postconceptional age, postnatal age, skin and rectal temperature, incubator temperature, weight, and transcutaneous oxygen tension on the reactive hyperaemia parameters could be found. We conclude that reactive hyperaemia of cutaneous blood flow can be elicited in premature newborn infants irrespective of postconceptional age, and that the hematocrit is inversely related to the time to reach maximal flow after occlusion. Key words: reactive hyperaemia, premature newborn, laser Doppler, cutaneous blood flow.

Reactive hyperaemia is the increase in blood flow in a part of the body, where circulation is restored after a period of occlusion (1). Following an occlusion, vasodilatation occurs, which is probably the result of a combination of physical and chemical factors, namely changes in transmural pressure (2) and accumulation of a dilator substance (j). Previous studies on reactive hyperaemia in newborn prematures have shown conflicting results. Some authors $(4,5)$ found a decreased reactive hyperaemia response and a lower baseline flow with increasing postconceptional age, whereas others $(6,7)$ reported an increasing reactive hyperaemia response and a higher baseline flow with increasing postconceptional age. Moreover, the earlier studies on reactive hyperaemia in newborn premature infants were done with venous occlusion plethysmography of the limbs, which reflects the blood flow of both skin and muscles $(4,6,8,9,10,11)$. This method does not discriminate between cutaneous and muscular blood flow. The present study was undertaken to determine if postocclusive reactive hyperaemia of cutaneous blood flow is present in premature newborns and if we could find changes in this response with increasing 
gestational, postconceptional and postnatal age. Therefore the reactive hyperaemia response of cutaneous blood flow of the forearm after a short term occlusion was determined in newborn infants of different postconceptional age, using a diode laser Doppler flowmeter applied to the skin.

\section{MATERIALS AND METHODS}

Twenty-four newborn infants of different postconceptional age were studied. Birthweight and gestational age varied from 0.80 to $3.77 \mathrm{~kg}$ (mean 1.53) and from 25.0 to 37.0 weeks (mean 30.5 ) respectively. Postconceptional age at time of the study ranged from 28.0 to 37.0 weeks (mean 32.5). Postnatal age varied from 0.3 to 72 days (mean 14.9). The infants were studied in incubators at their neutral environmental temperature according to Sauer et al. (12). None of the infants had cardiovascular disease. Infants receiving any medication that could possibly affect blood vessel tone were not included in the study. All infants were on a continuous feeding regimen by gavage and/or parenteral nutrition. Behavioral state was determined by observation and by assessment of respiration and heart rate according to the criteria of Prechtl \& O'Brien (13). Active sleep was seen during 146 of the 157 analysed occlusions.

Cutaneous blood flow at the site of the forearm was continuously measured before, during and after occlusion of the upper arm. To obtain occlusion a cuff was placed around the upper arm of the baby and insufflated to a pressure of $100 \mathrm{~mm} \mathrm{Hg}$. In each baby, ten consecutive occlusions of the upper arm lasting 1 min each, with 5 min intervals were done. Simultaneously, recordings were made of heart rate, respiratory rate (Hewlett Packard 78214-A), skin temperature on the chest and the forearm and of the rectal temperature (Yellow Springs thermistor probe $409 \mathrm{~B}$ ). Transcutaneous $\mathrm{pO}_{2}$ and $\mathrm{pCO}_{2}$ (Radiometer TCM2) were measured on the chest. All signals were recorded on an 8 channel strip chart recorder (Beckmann). Veneous hematocrit of each baby was measured on the same day by the coulter counter method (Coulter electronics).

Cutaneous blood flow was measured according to the laser Doppler method, described by others $(14,15)$. In the present study a recently developed diode laser Doppler flowmeter (Diodopp) was applied, which has the light source and detectors integrated in the sensor (16). Optical fibres, sensitive to movement artefacts, are therefore not used. The frequency shift of laser light, caused by the moving red blood cells, is used to determine blood flow in a small measuring volume of approximately $2-4 \mathrm{~mm}^{3}$ of the skin. The advantage of this method is that blood flow can be measured continuously and noninvasively over a long period without hardly any disturbance of the infant. The sensor was placed on the volar side of the forearm in each infant. After exclusion of the recordings disturbed by arm movements, a total of 157 measurements were analysed.

Data analysis. Laser Doppler flow is expressed in $\mathrm{mVolts}(\mathrm{mV})$. The preocclusional blood flow or baseline flow was defined as the mean cutaneous blood flow over $1 \mathrm{~min}$ prior to occlusion (Fig. 1). After occlusion the reactive hyperaemia response of the cutaneous blood flow was recorded. We measured the maximal blood flow after occlusion $\left(V_{\max }\right)$, and the time in seconds to reach the maximal response $\left(t_{\max }\right)$. Furthermore the time in seconds for blood flow to return to baseline after maximal flow $\left(t_{\text {end }}\right)$ and the percentage increase in cutancous blood flow above preocclusional level (overshoot) (17) were recorded. The mean values of the consecutive measurements in each infant were calculated. For statistical analysis the Pearson cross correlation test and multiple regression was used. A $p$ value of less than 0.05 was considered to be significant.

\section{RESULTS}

A representative recording of cutaneous blood flow before, during and after $1 \mathrm{~min}$ occlusion of the upperarm is shown in Fig. 1. We were able to detect a reactive hyperaemia response in every infant studied (Fig. 2). There was a large variability in the magnitude of the baseline flow and the reactive hyperaemia parameters as shown in Table 1. The baseline flow was $1954 \pm 934 \mathrm{mV}$, the $V_{\max }$ was $2640 \pm 1050$ $\mathrm{mV}$ and the overshoot was $74.6 \pm 34 \%$. The $t_{\max }$ and $t_{\mathrm{end}}$ were $35.6 \pm 14.6 \mathrm{sec}$ and $7.6 \pm 4.0 \mathrm{sec}$, respectively. All values are mean values $\pm \mathrm{SD}$. The $t_{\max }$ was inversely 


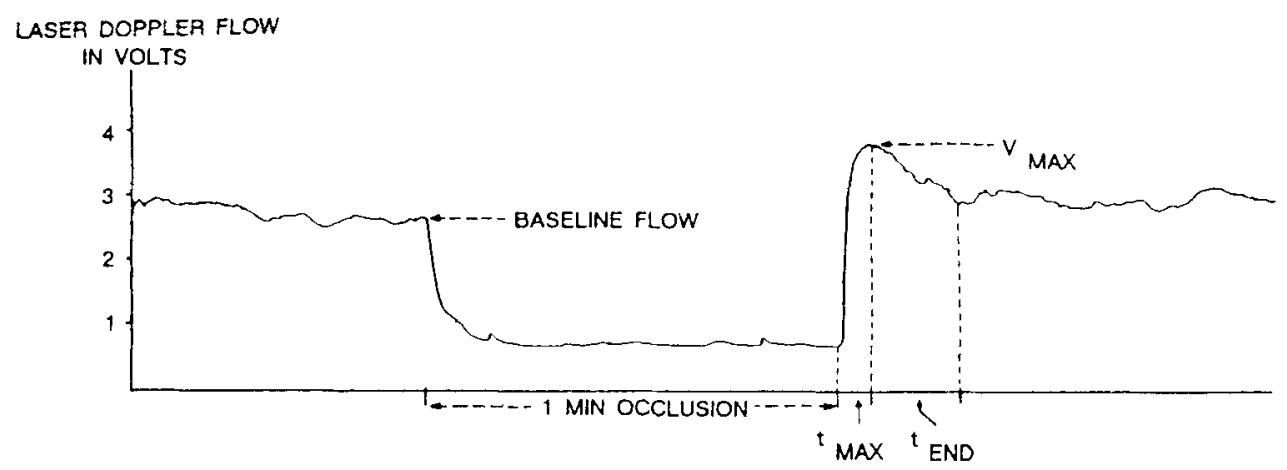

Fig. 1. Representative recording of cutaneous blood flow including a reactive hyperaemia after 1 min arterial occlusion.

correlated with the hematocrit, $r=-0.62, p<0.05$ (Fig. 3). There was no significant correlation between baseline flow or any of the other reactive hyperaemia parameters and the following variables: postconceptional and postnatal age, birthweight and skin, rectal and incubator temperature. During each occlusion we found a considerable decrease in transcutaneous oxygen tension, the mean decrease being $56.9 \% \pm 13.4 \%$ (mean $\pm \mathrm{SD}$ ) of the preocclusive level. The transcutaneous carbon dioxide tension increased slightly during occlusion with a maximum increase of 1 $\mathrm{mmHg}$. There was virtually no change in skin temperature during the recordings.

\section{DISCUSSION}

The results of our study show that a reactive hyperaemia response is elicitable in infants with a postconceptional age ranging from 28 weeks onwards. This indicates that this autoregulatory mechanism of blood supply in the skin exists in premature newborns. No influence of postconceptional age could be demonstrated. We found a variable baseline flow and variable reactive hyperaemia responses in individual

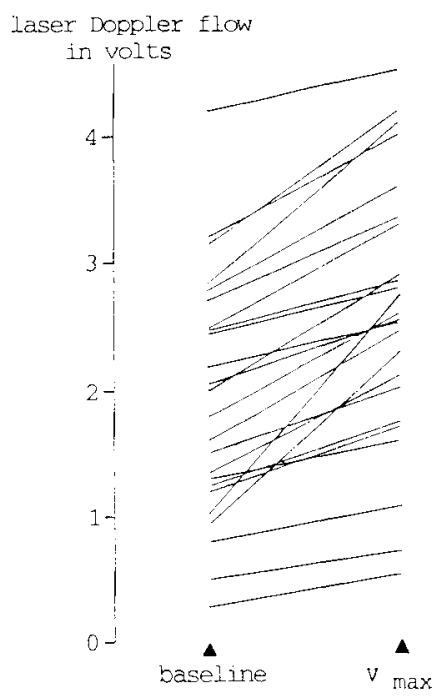

Fig. 2. Baseline cutaneous blood flow and increase to maximal postocclusive blood flow in all infants. 


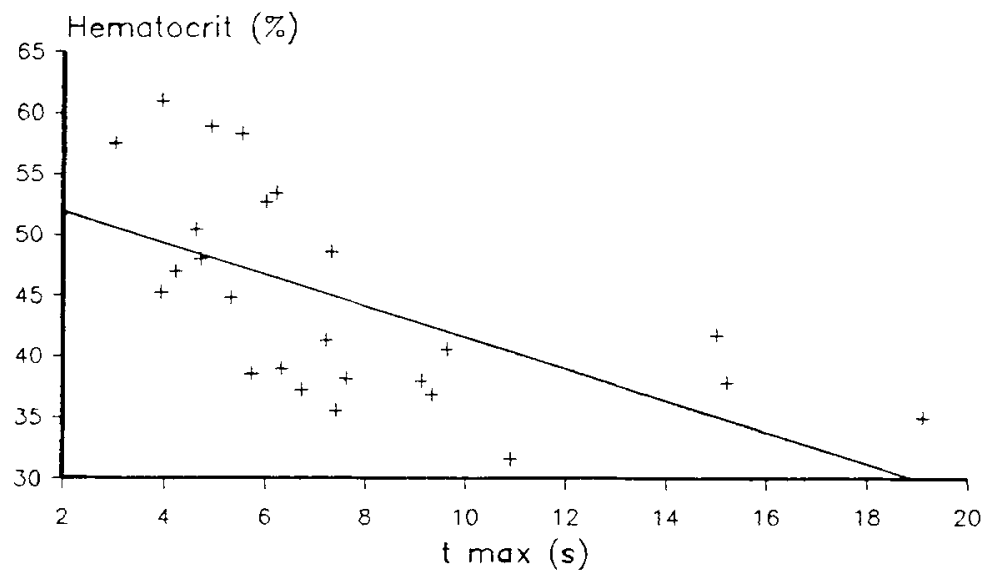

Fig. 3. Correlation $t_{\max }$ with venous hematocrit.

infants. The interindividual variability of the cutaneous blood flow and the reactive hyperaemia response were even more impressive. Large, sometimes more than tenfold, differences were seen. Laser Doppler skin blood flow recordings in adults show the same amount of variations in skin blood flow $(18,19)$ and in reactive hyperaemia parameters (19).

It is known that under resting conditions cutaneous blood flow varies continuously $(8,20)$. These variations are due to several mechanisms of central and local origin. The central nervous regulation mechanism is most important in the control of the vascular tone and, consequently, the cutaneous blood flow. Changing sympathetic activity causes vasomotor changes, which are a reflection of variations in the smooth muscle tension (21) and therefore in a variable cutaneous blood flow.

The locally originated regulation mechanisms such as hypoxia and hypercapnia are probably more important during the reactive hyperaemia following occlusion. The large variability in reactive hyperaemia can therefore be explained by changes in local factors, superimposed on a centrally regulated, variable cutaneous blood flow. The large interindividual variability in our study cannot be explained by different behavioral states, because 146 of the 157 analysed occlusions were recorded in infants during active sleep.

The reactive hyperaemia and baseline flow seem not to be influenced by postconceptional age, postnatal age or birthweight in our study. The literature on this subject is rather controversial. Berg \& Celander (4) found a higher maximal hyper-

Table 1. Summary of results

\begin{tabular}{llll}
\hline & Mean & SD & Range \\
\hline Baseline flow $(\mathrm{mV})$ & 1954 & 934 & $301-4214$ \\
$V_{\max }(\mathrm{mV})$ & 2640 & 1050 & $542-4525$ \\
Overshoot $(\%)^{a}$ & 74.6 & 34.0 & $7.4-138.7$ \\
$t_{\max }(\mathrm{s})$ & 7.6 & 4.0 & $3.0-19.1$ \\
$t_{\text {end }}(\mathrm{s})$ & 35.6 & 14.6 & $4.8-61.0$ \\
\hline
\end{tabular}

$" \%$ increase in preocclusive cutaneous blood flow. 
aemia response and a higher baseline flow in premature infants compared to term infants. Wu (5) found a decrease in cutaneous blood flow at rest with increasing postconceptional age. Riley (7) found a significantly greater blood flow in mature infants compared to premature infants, but found no effect of increasing maturity on blood flow in premature infants. The difference between all those studies and our study however is that we measured cutaneous blood flow alone, whereas Berg, Wu and Riley measured cutaneous and muscular blood flow together using venous occlusion plethysmography. Therefore it is difficult to compare our results with data obtained by venous occlusion plethysmography.

Rather surprising was the finding of a decreased $t_{\max }$ in infants with an increased systemic hematocrit (Fig. 3). Although the hematocrit in the microcirculation is only a fraction of the systemic hematocrit (22) and does not change in the same proportion as the systemic hematocrit (23), the changes in the microcirculatory hematocrit are likely to be in the same direction. In theory, the inverse correlation between systemic hematocrit and $t_{\text {max }}(r=-0.62, p=0.001)$ can be understood from the dynamic behaviour of flow in blood vessels. After relasing the cuff the onset of flow starts with an acceleration and the maximal flow will be reached sooner when the viscosity is increased, since the maximal flow is lower when vicosity, i.e. hematocrit is increased. The maximal flow, however, was not related to the hematocrit in the present study and therefore this explanation is unlikely.

It can also be assumed, that the hematocrit changes with increasing postconceptional age. Multiple regression, however, revealed a negligible influence of the postconceptional age on $t_{\max }$.

Mirhashemi et al. (23) suggested a specific effect in the skin circulation during hemodilution, in which arteriolar vasoconstriction is a compensatory mechanism, shifting the blood flow to other organs with higher oxygen demands. A reversed reaction, vasodilatation of cutaneous arterioles in case of higher hematocrits, might be possible. As the flow in the arterioles is only a small fraction of the flow measured by laser Doppler flowmetry and the arteriolar vasodilatation is most likely to influence only the first part of the reactive hyperaemia response, this might also be an explanation for the decreased $t_{\max }$ at higher hematocrits.

There is a difference in reactive hyperaemia after short term occlusion-usually defined as an occlusion shorter that 2 or 3 min-and after long term occlusion. It is known, that in long term occlusions, metabolic factors such as acidosis, hypercapnia and tissue lactic acid levels play an important role (24). The mechanism of reactive hyperaemia after a short term occlusion is not exactly known. One suggestion is that the vasodilatation after a short term occlusion is directed by hypoxia. Fairchild et al. (25) experimentally continued the hypoxia in dogs after release of the occlusion and found that the state of vasodilatation remained. We conclude that postocclusive reactive hyperaemia of the cutaneous circulation is well developed in premature newborns. An inverse correlation was found between hematocrit and time to reach maximal flow after occlusion. We found no change in the reactive hyperaemia response with increasing age. The large interindividual differences between reactive hyperacmia parameters and baseline flow indicate, however, that the transversal study design is less suitable in studying cutaneous blood flow. A longitudinal study seems more appropriate.

\section{ACKNOWLEDGEMENT}

This study was supported by the Netherlands Technology Foundation (S.T.W.) 


\section{REFERENCES}

1. Ganong WF. Review of medical physiology; 10th ed. California, Lange Medical Publications: 1981: 489-90.

2. Bayliss VM. On the local reactions of the arterial wall to changes of internal pressure. $\mathbf{J}$ Physiol 1902; 28: 220.

3. Shepard JT. Reactive hyperaemia in human extremities. Circ Res 1964; 14: 1/76-1/79.

4. Berg K, Celander O. Circulatory adaptation in the thermoregulation of full term newborn infants. Acta Paediatr Scand 1971; 60: 278-84.

5. Wu PYK. Peripheral blood flow in the neonate. I. Changes in total, skin and muscle blood flow with gestational and postnatal age. Pediatr Res $1980 ; 14 ; 1374-78$.

6. Celander O, Marild K. Reactive hyperaemia in the foot and calf of the newborn infant. Acta Paediatr 1962; 51: 544-52.

7. Riley ID. Hand and forearm blood flow in fullterm and premature infants. Clin Sci 1954; 13: 317-20.

8. Celander $\mathrm{O}$. Regional circulation and capillary filtration in relation to capillary exchange in the foot and calf on the newborn infant. Acta Paediatr 1962: 51: 385-400.

9. Kidd L. Limb blood flow in the normal and sick newborn. Am J Dis Child 1966; 112 : 402-07.

10. Bruck K. Hautdurchblutung und Thermoregulation bei neugeborenen Kindern. Pflügers Archiv 1957; 55-65.

11. Carlsson I, Wenmalm A. Effect of different prostaglandin synthesis inhibitors on postocclusive blood flow in human forearm. Prostaglandins 1983; 26: 241-52.

12. Sauer PJ, Dane HJ, Visser HK. Longitudinal studies on metabolic rate, heat loss and energy cost of growth in low birth weight infants. Pediatr Res 1984; 18: 254-59.

13. Prechtl HFR, O'Brien MJ. Behavioral states of the fullterm newborn. In: Stratton P. Psychobiology of the newborn. 1982: 21-52.

14. Nilsson GE, Tenland T, Oberg PA. Evaluation of a laser Doppler flow meter for measurement of tissue blood flow. IEEE Trans Biomed Eng 1980; 27: 12-19.

15. Stern MD, Lappe DL, Bowne PD et al. Continuous measurement of tissue blood flow by laser Doppler spectroscopy. Am J Physiol 1977; 232: 441-48.

16. Suichies HE, Aarnoudse JG, Okken A, Jentink HW, de Mul FFM, Greve J. Forehead skin blood flow in normal neonates during active and quiet sleep, measured with a diode laser Doppler instrument. Acta Paediatr Scand 1987; 77: 220-25.

17. Ninet J, Fronek A. Cutaneous postocclusive reactive hyperaemia monitored by laser doppler flux metering and skin temperature. Microvasc Res 1985; 30: 125-32.

18. Tenland T, Salerud EG, Nilsson GE, Oberg PA. Spatial and temporal variations in human skin blood flow. Int J Microcirc Clin Exp 1983; 2: 81-90.

19. Tooke JE, Ostergren J, Fagrell B. Synchronous assessment of human skin microcirculation by laser Doppler flowmetry and dynamic capillaroscopy. Int J Microcirc Clin Exp $1983 ; 2: 277-84$.

20. Salerud EG, Tenland T, Nilsson GE, Oberg PA. Rhythmical variations in human skin blood flow. Int J Microcirc Clin Exp 1983; 2: 91-102.

21. Fagrell B. Dynamics of skin microcirculation in humans. J Cardiovase Pharmacol 1985; 7; Suppl 3: 53-58.

22. Crystal GJ, Salem MR. Blood volume and hematocrit in regional circulations during isovolemic hemodilution in dogs. Microvasc Res 1989; 37: 237-40.

23. Mirhashemi S, Breit GA, Chavez Chavez RH, Intaglietta M. Effects of hemodilution on skin microcirculation. Am J Physiol 1988; 254: 411-16.

24. Kristensen $J K$. Excess cumulative blood flow and repayment during reactive hyperaemia in human cutaneous tissue. Acta Physiol Scand 1980; 108: 1-6.

25. Fairchild HM, Ross J, Guyton AC. Failure of recovery from reactive hyperaemia in the absence of oxygen. Am J Physiol 1966; 210: (3) 490-92.

(A. O.) Div. of Neonatology

Dept. of Paediatrics, University Hospital

Oostersingel 59

9713 EZ Groningen

The Netherlands 